\title{
Interaksi Perlakuan Mikoriza dan Inokulum Rhizobium sp Terhadap Pertumbuhan dan Pembentukan Bintil Akar Mucuna Bracteata
}

\section{Interaction of Micoriza and Inoculum Treatment of Rhizobium sp on Growth and Formation of Mucuna bracteata Nodule Roots}

\author{
Mardiana Wahyuni 1 ${ }^{\text {**, }}$, Ricky Elmando Saragih ${ }^{2)}$, Mariani Sembiring ${ }^{3)}$ \\ ${ }^{1,2}$ Sekolah Tinggi Ilmu Pertanian Agrobisnis Perkebunan Medan \\ ${ }^{3}$ Fakultas Pertanian Universitas Sumatera Utara, Indonesia \\ *E-mail : mardiana@stipap.ac.id
}

\begin{abstract}
The purpose of this study was to determine the effect of mycorrhizal treatment and inoculation of Rhizobium sp on the growth and formation of Mucuna bracteata root nodules. The study was conducted in the STIPAP Medan experimental garden. The study was conducted in April - July 2019. The study used 2 factorial randomized block design (RBD) methods consisting of 3 and 3 treatments with 4 replications, so that the total sample was 36 seedlings. Parameters observed were length of tendrils, number of leaves, number of root nodules, dry weight of root nodules, chlorophyll content, leaf $N$ content and the degree of root infection. The data obtained were statistically analyzed by analysis of variance (ANOVA) with the test 5\% significant difference. The results showed that the best single treatment of Mikoriza in this study was M2 with a dose of $40 \mathrm{~g} / \mathrm{seed}$, which affected in length of tendrils. Rhizobium sp application significantly affected the length of tendrils, number of leaves, number of nodules at the best single treatment is $R 2$ with a dose of $0.6 \mathrm{ml} / \mathrm{seed}$. Interaction of mycorrhizal and Rhizobium sp treatment showed a significant effect on M2R2 treatment, namely mycorrhizal application with a dose of $40 \mathrm{~g} / \mathrm{seed}$ and Rhizobium $\mathrm{sp}$ application with a dose of $0.6 \mathrm{ml} / \mathrm{seed}$ had the best growth for several observational parameters.
\end{abstract}

Keywords: Mycorrhizae, Mucuna bracteata, Rhizobium sp, Root Nodule, Vegetative.

Disubmit : 29 Oktober 2019, Diterima: 27 Februari 2020, Disetujui : 25 Agustus 2020

\section{PENDAHULUAN}

Penanaman tanaman kacangan sebagai penutup tanah di perkebunan kelapa sawit bertujuan untuk memperkecil erosi, memperkaya bahan organik, memperbaiki struktur tanah dan menekan pertumbuhan gulma seperti Imperata cylindrical, Mikania micrantha, pakisan, dan gulma lainnya sehingga dapat menghemat biaya perawatan tanaman sawit, khususnya pada masa Tanaman Belum Mengasilkan (TB) (Harahap, dkk., 2011). Mucuna bracteata (MB) adalah jenis Legume Cover Crops (LCC) yang saat ini banyak digunakan oleh perkebunan-perkebunan kelapa sawit dan karet (Siagian, N., Tistama, R., 2005)

Peran tanaman $M$. bracteata ini sangat penting karena dapat menambah kesuburan tanah, akar-akarnya bersimbiosis dengan bakteri Rhizobium sp yang mampu mengikat Nitrogen (N2) dari udara. Nitrogen bebas yang diikat tersebut, kemudian disimpan dalam bentuk bintil-bintil akar yang mengandung nitrogen yang berfungsi untuk memperbaiki kesuburan tanah (Fachruddin, 2007) 
Tanaman Mucuna bracteata dapat dijadikan pilihan utama sebagai sumber pupuk hijau atau kompos, selain karena kandungan haranya terutama $\mathrm{N}$ relatif lebih tinggi dibandingkan tanaman non legum, penyediaan haranya juga lebih cepat karena relatif lebih mudah terdekomposisi, dengan $\mathrm{C} / \mathrm{N}$ yang rendah (Mazidah dkk, 2014)

Menurut Sari, (2015) terbentuknya nodula akar dimulai dengan bakteri menginfeksi dan melakukan penetrasi ke dalam akar. Sel akar Mucuna bracteata yang telah terinfeksi ini terbagi membentuk jaringan nodula di mana bakteri ini membelah dan menggandakan diri. Jaringan nodula tumbuh dalam berbagai ukuran, mendorong dirinya melalui akar dan kemudian muncul sebagai tambahan dalam sistem perakaran.

Efektivitas bakteri Rhizobium sangat tergantung pada kecocokan sumber inokulum dengan tanaman inang. Apabila terjadi kecocokan dengan tanaman inang, maka akan terjadi simbiosis yang efektif. Simbiosis antara Rhizobium dengan spesies leguminosae terdapat perbedaan dalam spesifikasinya antara strain-strain Rhizobium dengan varietas tanaman legume (Surtiningsih T, 2009)

FMA (Fungi Mikoriza Arbuskular) adalah salah satu jasad renik tanah dari kelompok jamur yang bersimbiosis dengan akar tanaman. Jamur ini mempunyai sejumlah pengaruh yang menguntungkan bagi tanaman yang bersimbiosis dengannya (Hapsoh. H, 2008). Simbiosis antara FMA dengan perakaran tanaman bersifat mutualistik atau saling menguntungkan karena tanaman inang memberi sebagian fotosintesis pada fungi, sebaliknya tanaman inang mendapatkan nutrient dari fungi (Rini \& Rozalinda, 2012)

Hanum, (2006) menambahkan bahwa pemanfaatan FMA pada tanaman kedelai membantu meningkatkan potensi sistem perakaran tanaman untuk mengabsorbsi air dan unsur hara.

FMA mampu meningkatkan pertumbuhan tanaman karena status hara tanaman tersebut dapat ditingkatkan dan diperbaiki. Kemampuannya yang tinggi dalam meningkatkan penyerapan air dan hara terutama P. FMA yang menginfeksi sistem perakaran tanaman inang akan memproduksi jalinan hifa secara intensif sehingga tanaman bermikoriza akan mampu meningkatkan kapasitasnya dalam menyerap unsur hara dan air. Penelitian ini bertujuan untuk mengetahui pengaruh perlakuan Mikoriza dan Inokulum Rhizobium sp terhadap pertumbuhan dan pembentukan bintil akar Mucuna Bracteata.

\section{METODE PENELITIAN}

Penelitian dilaksanakan di Areal Sekolah Tinggi Ilmu Pertanian Agrobisnis Perkebunan (STIPAP) Medan pada April - Juli 2019. Bahan yang digunakan yaitu, biji Mucuna bracteata, Inokulum Rhizobium sp dengan kepadatan 106 spora/ml, Fungi Mikoriza arbuskular, tanah top soil sebagai media tumbuh, Polybag 40 x $15 \mathrm{~cm}$, bambu dan paranet. Peralatan yang digunakan yaitu, cangkul, pipet tetes, kawat, pisau, Klorofilmeter, timbangan digital dan meteran kain.

Adapun tahapan penelitian yang dilakukan adalah:

> Pembibitan Mucuna bracteata biji; dikecambahakan dalam plastic 10 x $12 \mathrm{~cm}$ dengan diisi tanah; pada waktu \pm 1 minggu setelah $\mathrm{M}$. bracteata tumbuh, kemudian dipindahkan ke polibeg yang diisi $3 \mathrm{~kg}$ tanah.

Mikoriza ditaburkan ke dalam tanah dalam polibeg sebelum bibit dalam p;astik kecil dimasukkan ke polibeg agar perakaran M. bracteata dapat segera bersinggungan dengan FMA.

> Isolat Rhizobium sp dengan kepadatan 106 spora/ml diaplikasikan dengan pipet tetes dengan kalibrasi 1 $\mathrm{ml}$ adalah 20 tetes.

Rancangan yang digunakan yaitu, Rancangan Acak Kelompok (RAK) Faktorial dua faktor. Faktor I adalah Perlakuan Mikoriza terdiri dari 3 taraf yaitu M0 (0 g/tanaman), M1 (20 g/tanaman), M2 (40 g/tanaman). Faktor II adalah perlakuan Inokulasi Rhizobium sp. terdiri dari 3 taraf yaitu R0 (0 ml/tanaman), $\mathrm{R} 1$ (0,3 $\mathrm{ml} /$ tanaman), $\mathrm{R} 2$ ( $0,6 \mathrm{ml} /$ tanaman).

Pengamatan yang dilakukan adalah panjang sulur, jumlah daun, jumlah bintil akar, berat kering bintil akar, berat kering akar,kadar hara $\mathrm{N}$ daun, derajat infeksi akar dan kadar klorofil daun. 


\section{HASIL DAN PEMBAHASAN}

Panjang Sulur. Menurut Fakuara (1998) faktor yang berpengaruh terhadap efektivitas mikoriza adalah suhu, kelembaban dan sinar matahari. Terbentuknya hifa - hifa eksternal memperpanjang luas permukaan sehingga absorsbsi hara dapat meningkat. Hasil pengamatan dan analisa sidik ragam disajikan pada Tabel 1.

Tabel 1 Rekapitulasi Hasil Pengamatan Panjang Sulur Mucuna bracteata

\begin{tabular}{|c|c|c|c|c|c|c|c|c|c|c|c|c|}
\hline Perlakuan & \multicolumn{2}{|c|}{2 MST } & \multicolumn{2}{|c|}{4 MST } & \multicolumn{2}{|c|}{6 MST } & \multicolumn{2}{|c|}{8 MST } & \multicolumn{2}{|c|}{10 MST } & \multicolumn{2}{|c|}{12 MST } \\
\hline MOR0 & 6.5 & & 22.3 & & 37.8 & & 55.8 & & 105.8 & & 137.0 & \\
\hline M0R1 & 9.3 & & 34.0 & & 72.3 & & 96.8 & & 146.0 & & 178.3 & \\
\hline M0R2 & 10.0 & & 36.3 & & 70.3 & & 115.8 & & 171.0 & & 195.8 & \\
\hline M1R0 & 8.8 & & 35.0 & & 64.3 & & 100.3 & & 151.8 & & 177.3 & \\
\hline M1R1 & 12.8 & & 67.8 & & $\begin{array}{c}109 . \\
8\end{array}$ & & 158.3 & & 217.8 & & 248.3 & \\
\hline M1R2 & 10.5 & & 43.0 & & 71.3 & & 103.0 & & 148.5 & & 176.8 & \\
\hline M2R0 & 9.3 & & 36.8 & & 69.0 & & 93.8 & & 151.5 & & 180.3 & \\
\hline M2R1 & 11.0 & & 48.5 & & 78.5 & & 112.8 & & 155.0 & & 183.3 & \\
\hline M2R2 & 12.5 & & 56.8 & & 97.5 & & 154.5 & & 212.8 & & 240.5 & \\
\hline Rataan & 10.1 & & 42.3 & & 74.5 & & 110.1 & & 162.2 & & 190.8 & \\
\hline Mo & 11.4 & 100.0 & 41.1 & 100.0 & 80.1 & 100.0 & 119.2 & 100.0 & 187.9 & $\begin{array}{c}100 . \\
0\end{array}$ & 227.1 & 100.0 \\
\hline M1 & 14.2 & 124.3 & 64.8 & 157.6 & 109.0 & 136.1 & 160.7 & 134.8 & 230.2 & $\begin{array}{c}122 . \\
5\end{array}$ & 267.7 & 117.9 \\
\hline M2 & 14.6 & 127.2 & 63.1 & 153.5 & 108.9 & 135.9 & 160.4 & 134.6 & 230.8 & $\begin{array}{c}122 . \\
8\end{array}$ & 268.4 & 118.2 \\
\hline Ro & 10.9 & 100.0 & 41.8 & 100.0 & 76.0 & 100.0 & 111.0 & 100.0 & 181.8 & $\begin{array}{c}100 . \\
0\end{array}$ & 219.8 & 100.0 \\
\hline R1 & 14.7 & 134.7 & 66.8 & 159.8 & 115.8 & 152.3 & 163.4 & 147.2 & 230.6 & $\begin{array}{c}126 . \\
8\end{array}$ & 271.0 & 123.3 \\
\hline $\mathbf{R} 2$ & 14.7 & 134.7 & 60.4 & 144.7 & 106.2 & 139.8 & 165.9 & 149.4 & 236.6 & $\begin{array}{c}130 . \\
1 \\
\end{array}$ & 272.4 & 124.0 \\
\hline Uji F & F hit & & F hit & & F hit & & F hit & & F hit & & F hit & \\
\hline $\mathbf{M}$ & $2,3 \mathrm{tn}$ & & $4,2^{*}$ & & $2,7 \mathrm{tn}$ & & $3,1 \mathrm{tn}$ & & $2,2 \mathrm{tn}$ & & $2,0 \mathrm{tn}$ & \\
\hline $\mathbf{R}$ & $3,8^{*}$ & & $4,1^{*}$ & & $4,2^{*}$ & & $5,3^{*}$ & & $3,3 \mathrm{tn}$ & & $3,2 \mathrm{tn}$ & \\
\hline MXR & $0,4 \mathrm{tn}$ & & $1,1 \mathrm{tn}$ & & $1,3 \mathrm{tn}$ & & $2,2 \mathrm{tn}$ & & $2,5 \mathrm{tn}$ & & $2,4 \mathrm{tn}$ & \\
\hline
\end{tabular}

Keterangan : Satuan cm ; MST : Minggu Setelah Tanam* : Nyata; ** : Sangat Nyata; tn : Tidak Nyata

Pada perlakuan Mikoriza menunjukkan pengaruh yang berbeda nyata pada pengamatan ke 4 MST. Perlakuan tunggal terbaik pada $12 \mathrm{MST}$ adalah aplikasi M2 dosis $40 \mathrm{~g} /$ tanaman dengan indeks peningkatan $18 \%$ dibandingkan M0 (0g/tanaman).

Perlakuan Rhizobium sp menunjukkan pengaruh yang berbeda nyata pada pengamatan 2 sampai 8 MST. Perlakuan tunggal terbaik pada 12 MST adalah aplikasi R2 dengan dosis 0,6 ml/tanaman dengan indeks peningkatan $24 \%$.

Interaksi perlakuan Mikoriza dan inokulum Rhizobium sp sampai pada pengamatan 12 MST tidak menunjukkan pengaruh yang berbeda nyata terhadap pertumbuhan panjang sulur Mucuna bracteata. Meskipun demikian interaksi keduanya tetap menunnjukkan peningkatan terhadap pertumbuhan panjang sulur Mucuna bracteata. Hal ini sejalan dengan pendapat (Padmowihardjo, 2014) pada kondisi yang terbaik pertumbuhan Mucuna bracteata dapat menutup tanah mencapai $2-3 \mathrm{~m}^{2}$ perbulan. Supriyanto, (1999) menyatakan bahwa penggunaan mikoriza merupakan salah satu upaya yang dapat dilakukan untuk mempercepat pertumbuhan tanaman. 
Jumlah Daun. Perlakuan Mikoriza tidak berpengaruh nyata terhadap jumlah daun Mucuna bracteata. Pada perlakuan Rhizobium sp menunjukkan pengaruh yang nyata pada pengamatan ke 10 MST dan 12 MST. Jumlah daun terbanyak pada perlakuan R2 dengan indeks peningkatan jumlah 23\% pada pengamatan 12 MST. Interaksi perlakuan Mikoriza dan inokulum Rhizobium sp menunjukkan pengaruh yang berbeda nyata terhadap pertumbuhan jumlah daun Mucuna bracteata. Hasil pengamatan dan analisa sidik ragam disajikan pada Tabel 2.

Tabel 2 Rekapitulasi Hasil Pengamatan Jumlah daun Mucuna bracteata (helai)

\begin{tabular}{|c|c|c|c|c|c|c|c|c|c|c|c|c|}
\hline Perlakuan & \multicolumn{2}{|c|}{$2 \mathrm{MST}$} & \multicolumn{2}{|c|}{4 MST } & \multicolumn{2}{|l|}{6 MST } & \multicolumn{2}{|c|}{8 MST } & \multicolumn{2}{|l|}{10 MST } & \multicolumn{2}{|l|}{12 MST } \\
\hline M0R0 & 5.3 & & 15.3 & & 21.3 & & 24.3 & & 35.0 & & 42.0 & \\
\hline M0R1 & 5.5 & & 13.5 & & 19.3 & & 23.8 & & 35.8 & & 42.3 & \\
\hline M0R2 & 4.5 & & 16.5 & & 21.0 & & 23.3 & & 36.0 & & 42.0 & \\
\hline M1R0 & 4.5 & & 14.8 & & 17.5 & & 23.3 & & 28.3 & & 36.0 & \\
\hline M1R1 & 4.5 & & 19.0 & & 23.8 & & 28.3 & & 48.0 & & 53.5 & \\
\hline M1R2 & 4.8 & & 14.0 & & 21.5 & & 27.0 & & 39.3 & & 45.5 & \\
\hline M2R0 & 3.8 & & 15.3 & & 20.5 & & 26.0 & & 36.0 & & 41.3 & \\
\hline M2R1 & 4.0 & & 17.0 & & 21.5 & & 27.5 & & 40.8 & & 46.3 & \\
\hline M2R2 & 5.0 & & 20.5 & & 24.8 & & 30.3 & & 55.3 & & 59.8 & \\
\hline Rataan & 4.6 & & 16.2 & & 21.2 & & 25.9 & & 39.4 & & 45.4 & \\
\hline M0 & 6.8 & 100 & 20.1 & 100 & 27.3 & 100 & 31.7 & 100 & 47.4 & 100 & 56.1 & 100 \\
\hline M1 & 6.1 & 90 & 21.2 & 106 & 27.9 & 102 & 34.9 & 110 & 51.3 & 108 & 60.0 & 107 \\
\hline M2 & 5.7 & 84 & 23.4 & 117 & 29.7 & 109 & 37.2 & 118 & 58.7 & 124 & 65.4 & 117 \\
\hline RO & 6.0 & 100 & 20.1 & 100 & 26.3 & 100 & 32.7 & 100 & 44.1 & 100 & 53.0 & 100 \\
\hline R1 & 6.2 & 104 & 22.0 & 109 & 28.7 & 109 & 35.3 & 108 & 55.3 & 125 & 63.1 & 119 \\
\hline $\mathbf{R} 2$ & 6.3 & 106 & 22.7 & 113 & 29.9 & 114 & 35.8 & 110 & 58.0 & 131 & 65.4 & 123 \\
\hline Uji F & F hit & & F hit & & F hit & & F hit & & F hit & & F hit & \\
\hline $\mathbf{M}$ & $2,1 \mathrm{tn}$ & & $1,1 \mathrm{tn}$ & & $0,7 \mathrm{tn}$ & & $3,3 \mathrm{tn}$ & & $2,6 \mathrm{tn}$ & & $2,5 \operatorname{tn}$ & \\
\hline $\mathbf{R}$ & $0,2 \mathrm{tn}$ & & $0,7 \mathrm{tn}$ & & $1,5 \mathrm{tn}$ & & $1,2 \mathrm{tn}$ & & $4,4 *$ & & $4,9 *$ & \\
\hline MXR & $1,4 \mathrm{tn}$ & & $1,6 \mathrm{tn}$ & & $1,4 \mathrm{tn}$ & & $0,9 \mathrm{tn}$ & & $2,6 \mathrm{tn}$ & & $3,1^{*}$ & \\
\hline
\end{tabular}

Keterangan : Satuan cm ; MST : Minggu Setelah Tanam * : Nyata; ** : Sangat Nyata; tn : Tidak Nyata

Prawiranata et.al (1981) menyatakan bahwa peningkatan laju fotosintesis akan diiringi dengan peningkatan jumlah daun. Karena apabila jumlah daun sedikit fotosintesis akan berjalan lambat dan sebaliknya. Hal ini sejalan dengan hasil penelitian (Rachmawati H, 2011) bahwa aplikasi CMA pada berbagai dosis memberikan pengaruh yang lebih baik terhadap pertumbuhan bibit tanaman lada dibandingkan dengan perlakuan tanpa CMA.

Jumlah Bintil Akar, dan Berat Kering Akar. Perlakuan mikoriza berpengaruh nyata terhadap jumlah bintil akar pada perlakuan M1 jumlah bintil akar meningkat 42\%. Hal ini disebabkan dengan aplikasi mikoriza dapat memperluas bidang kontak akar dengan tanah yang diinokulasi dengan bakteri Rhizobium sehingga terbentuk nodul. Hasil pengamatan dan analisa sidik ragam disajikan pada Tabel 3.

Perlakuan Rhizobium berpengaruh sangat nyata terhadap jumlah bintil akar, dengan peningkatan 250 $350 \%$. Sehubungan dengan belum diketahuinya spesifikasi bakteri Rhizobium untuk Mucuna bracteata maka Rhizobium $s p$ yang digunakan pada penelitian ini efektif. Dengan keberhasilan ini diharapkan dapat juga diaplikasikan pada penanaman Mucuna bracteata di perkebunan kelapa sawit sehingga dapat mempercepat pembentukan bintil akarnya. Interaksi perlakuan mikoriza dan Rhizobium berpengaruh nyata terhadap pembentukan bintil akar. Perlakuan terbaik terdapat pada M1R1 sebagai kondisi optimumnya. 
Tabel 3. Rekapitulasi Hasil Pengamatan Jumlah Bintil Akar, Berat Bintil Akar, dan Berat Kering Akar

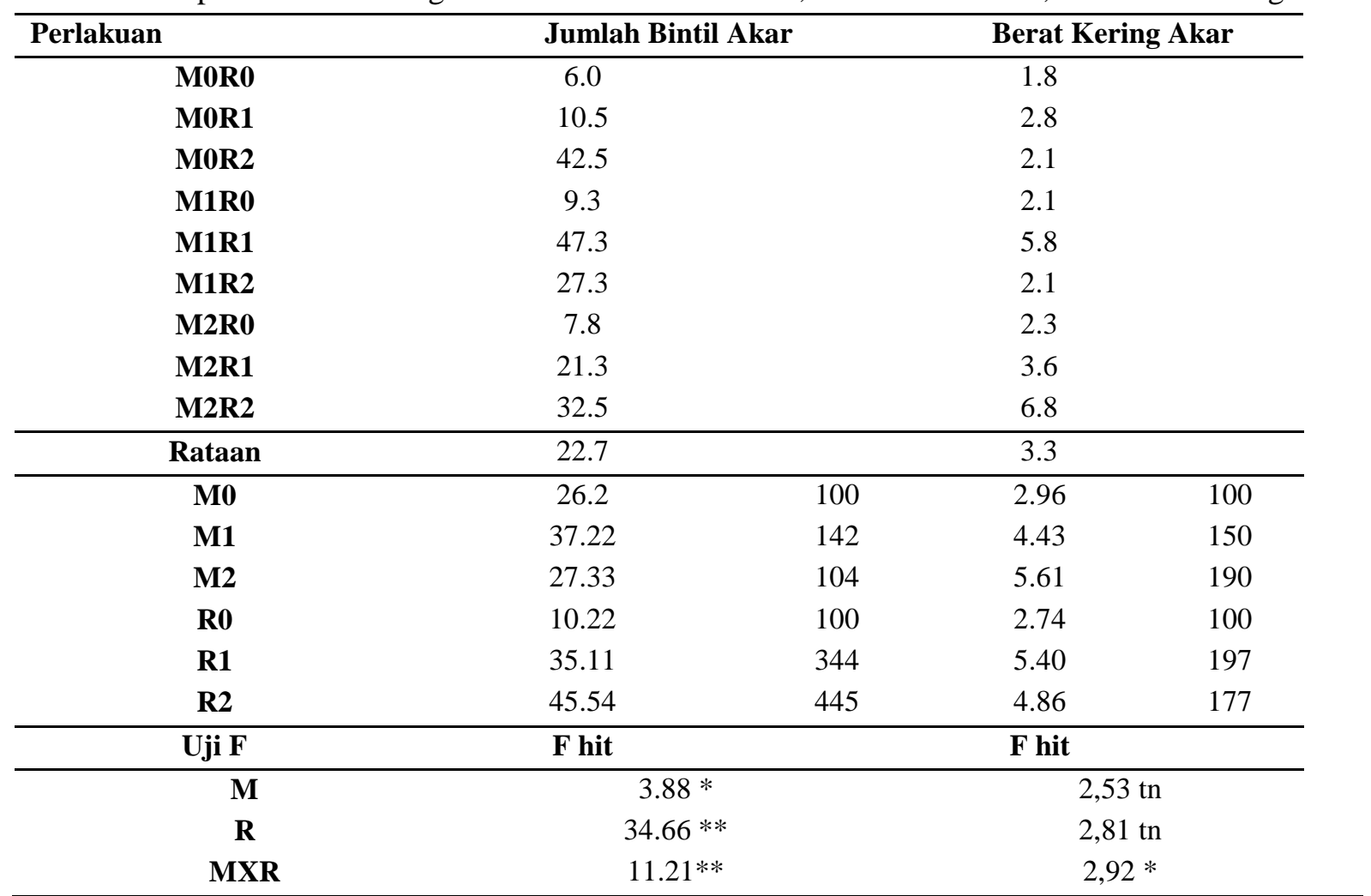

Keterangan: MST : Minggu Setelah Tanam; * Nyata; ** : Sangat Nyata; tn : Tidak Nyata

Perlakuan Mikoriza tidak berpengaruh nyata terhadap berat kering akar. Perlakuan tunggal terbaik terdapat pada M2 (dosis 40 gram/bibit) sebesar 5,61 gram dengan indeks peningkatan sebesar $90 \%$. Pada perlakuan Rhizobum sp tidak menunjukkan pengaruh nyata terhadap berat kering akar. Perlakuan tunggal terbaik pada R1 (dosis 0,3 ml/bibit) yaitu sebesar 5,40 gram dengan indeks peningkatan sebesar $97 \%$. Interaksi perlakuan Mikoriza dan inokulum Rhizobium sp menunjukkan pengaruh nyata terhadap berat kering akar pada taraf uji $5 \%$.

Hasil penelitian Widiastuti dan Sukarno, (2005) perlakuan inokulasi spora Acaulospora tuberculata dengan 3 dosis jumlah spora (200, 350 dan 500 spora) pada bibit kelapa sawit menunjukkan bahwa perlakuan 500 spora A. tuberculata berpengaruh nyata dalam meningkatkan bobot basah tajuk, bobot kering akar dan total bobot basah dan kering bibit kelapa sawit.

Menurut Salwani, dkk (2012) saat microsymbionts berhasil menginfeksi akar dan membentuk bintil akar pada $M$. bracteata maka proses penambatan N2 mulai terjadi untuk memasok sumber nitrogen yang dibutuhkan untuk pertumbuhan tanaman yang ditunjukkan dengan meningkatnya produksi bobot kering tajuk (biomas).

Menurut Bertham YH, (2002) bahwa jumlah bintil akar merupakan indikator keberhasilan inokulasi Rhizobium yang sering digunakan untuk menilai pengaruhnya terhadap pertumbuhan dan hasil tanaman legume seperti kedelai.

Kadar Klorofil Daun dan Kadar Hara N. Perlakuan Mikoriza tidak berpengaruh nyata terhadap kadar klorofil daun Mucuna bracteata. Perlakuan tunggal terbaik pada M2 (dosis 40 gram/bibit) sebesar 39,4 $\mathrm{CCl}$ dengan indeks peningkatan sebesar $17 \%$. Perlakuan Rhizobium sp tidak berpengaruh nyata terhadap kadar klorofil daun Mucuna bracteata. Interaksi perlakuan Mikoriza dan inokulum Rhizobium sp tidak berpengaruh nyata terhadap kadar klorofil daun. Hasil pengamatan dan analisa sidik ragam disajikan pada Tabel 4. 
Tabel 4. Rekapitulasi Hasil Pengamatan Kadar Klorofil Daun (CCI) dan Kadar Hara N (\%)

\begin{tabular}{|c|c|c|c|c|c|}
\hline & \multirow[b]{2}{*}{ Perlakuan } & \multicolumn{2}{|c|}{ Kadar Klorofil Daun } & \multicolumn{2}{|c|}{ Kadar Hara N (\%) } \\
\hline & & 3 BST & & $\begin{array}{c}\text { Kadar N } \\
(\%)\end{array}$ & Kategori \\
\hline & MOR0 & 24.6 & & 3.10 & $\mathbf{T}$ \\
\hline & MOR1 & 25.0 & & 3.02 & $\mathbf{T}$ \\
\hline & M0R2 & 26.2 & & 3.30 & $\mathbf{T}$ \\
\hline & M1R0 & 32.0 & & 3.16 & $\mathbf{T}$ \\
\hline & M1R1 & 29.0 & & 3.10 & $\mathbf{T}$ \\
\hline & M1R2 & 25.3 & & 3.00 & $\mathbf{T}$ \\
\hline & M2R0 & 28.2 & & 3.12 & $\mathbf{T}$ \\
\hline & M2R1 & 27.5 & & 3.20 & $\mathbf{T}$ \\
\hline & M2R2 & 32.9 & & 3.17 & $\mathbf{T}$ \\
\hline & Jumlah & 500.9 & & 3.1 & \\
\hline & Rataan & 27.8 & Indeks & & \\
\hline M0 & & 33.6 & 100 & 3.14 & 100 \\
\hline M1 & & 38.3 & 114 & 3.09 & 98 \\
\hline M2 & & 39.4 & 117 & 3.16 & 101 \\
\hline R0 & & 37.6 & 100 & 3.13 & 100 \\
\hline $\mathbf{R} 1$ & & 36.2 & 96 & 3.11 & 99 \\
\hline $\mathbf{R 2}$ & & 37.5 & 100 & 3.16 & 102 \\
\hline & Uji F & F hit & & & \\
\hline M & & 2,9 tn & & & \\
\hline $\mathbf{R}$ & & 0,2 tn & & & \\
\hline MXR & & 1,8 tn & & & \\
\hline
\end{tabular}

Keterangan: MST : Minggu Setelah Tanam, tn : Tidak Nyata

Pembentukan klorofil atau zat hijau daun terutama dipengaruhi oleh kadar Mg yang ada dalam tanah maupun dari pupuk yang diaplikasikan (Wahyuni, 2019). Sehubungan pada penelitian ini tidak ada aplikasi pupuk Mg maka perlakuan juga tidak mempengaruhi jumlah klorofil daun. Kadar $\mathrm{N}$ dan seluruh perlakuan tanaman kategori tinggi.

Penambatan $\mathrm{N}$ dilakukan oleh adanya simbiosis dengan bakteri yaitu Rhizobium sp. Diperlukan kondisi lingkungan atau tempat tumbuh yang baik sehingga pertumbuhan Mucuna bracteata dan penambatan $\mathrm{N}$ dapat berlangsung dengan baik. (Harahap, dkk S., 2011) mengemukakan bahwa salah satu tujuan penanaman Mucuna bracteata di perkabunan kelapa sawit ataupun karet untuk menambah unsur $\mathrm{N}$ dari biomassanya.

Derajat Infeksi Akar. Perlakuan aplikasi Mikoriza yang memiliki derajat infeksi akar tertinggi pada perlakuan tunggal M2 (dosis 40 gram/bibit) adalah 66,7\% dengan penambahan sebesar 16,7\% dibanding M1. Hal ini dapat dikatakan semakin tingginya dosis yang diberikan maka semakin banyak infeksi mikoriza pada akar. Hasil pengamatan dan analisa sidik ragam disajikan pada Tabel 5.

Penginfeksian akar yang dilakukan mikooriza dapat dikatakan mencapai nilai yang baik, hal ini dikarenakan terdapat faktor pendukung tumbuhnya mikoriza yaitu media tanam yang teksturnya sedang kecukupan air sehingga proses infeksi berjalan dengan baik. Simarmata, (2007) juga menyatakan bahwa keefektifan mikoriza tersebut tentu berkaitan erat dengan berbagai faktor lingkungan tanah abiotik (konsentrasi hara, $\mathrm{pH}$, kadar air, temperatur, pengolahan tanah dan penggunaan pupuk/pestisida) dan faktor biotik (interaksi mikroba, spesies cendawan, tanaman inang, tipe perakaran tanaman inang, dan kompetisi antar cendawan mikoriza). 
Tabel 5. Rekapitulasi Hasil Pengamatan Derajat Infeksi Akar (\%)

\begin{tabular}{lccc}
\hline & Perlakuan & Rataan $(\%)$ & \\
\hline & M0R0 & 0 & \\
& M0R1 & 0 & \\
& M0R2 & 0 & \\
& M1R0 & 50 & \\
& M1R1 & 50 & \\
& M1R2 & 50 & 0 \\
& M2R0 & 60 & 50.0 \\
& M2R1 & 65 & 16.7 \\
& M2R2 & 75 & 0 \\
\hline M0 & Rataan & 38.9 & 1.6 \\
M1 & & 0 & 3.4 \\
M2 & & 50 & Penambahan \\
R0 & & 66.7 & \\
R1 & & 36.7 & \\
R2 & & 38.3 & \\
\hline
\end{tabular}

Keterangan : Satuan Persen (\%)

Hal ini juga sejalan dengan penelitian dari (Syamsiyah, dkk, 2012) yang menyatakan bahwa serapan hara $\mathrm{N}$ dan $\mathrm{P}$ yang tinggi terdapat pada tanaman yang diberi mikoriza, disebabkan mikoriza akan mendorong berkembangnya hifa pada akar tanaman yang selanjutnya akan membantu penyerapan hara.

\section{KESIMPULAN}

Aplikasi Mikoriza dapat meningkatkan pertumbuhan panjang sulur Mucuna bracteata, dengan perlakuan tunggal terbaik pada penelitian ini adalah M2 dengan dosis 40 gram/bibit. Aplikasi Rhizobium sp berpengaruh nyata terhadap panjang sulur, jumlah daun, jumlah bintil akar pada perlakuan tunggal terbaik adalah R2 dengan dosis $0,6 \mathrm{ml} /$ bibit. Interaksi perlakuan Mikoriza dan Rhizobium sp menunjukkan pengaruh yang nyata pada perlakuan M2R2 yaitu aplikasi Mikoriza dengan dosis 40 gram/bibit dan aplikasi Rhizobium sp dengan dosis $0,6 \mathrm{ml} / \mathrm{bibit}$ memiliki pertumbuhan terbaik untuk beberapa parameter pengamatan.

\section{DAFTAR PUSTAKA}

Bertham YH. (2002). Ketergantungan terhadap MVA dan serapan hara fosfor tiga galur tanaman kedelai (Glycine max L) pada tanah ultisol Bengkulu. JIPI, 4((1)), 49-55.

Fachruddin, L. (2007). Budidaya Kacang-kacangan. Yogyakarta: Kansius.

Hanum, C. (2006). Pemanfaatan Mikoriza Vesicular Arbuscular (MVA) untuk Peningkatan Pertumbuhan dan Produksi Kedelai pada Lahan Kering Ultisol. Diakses dari http://pustaka.litbang.deptan.go.id pada tanggal 10 Oktober 2019. 67-72. Universitas Sumatera Utara, Medan.

Hapsoh. H. (2008). Pemanfaatan Fungi Mikoriza Arbuskula pada Budidaya Kedelai di Lahan Kering. Universitas Sumatera Utara. Medan.

Harahap, I.Y., Hidayat, T.C., Pangaribuan, Y., Simangunsong, G., Sutarta, E.D.,Pangaribuan, Y., Listia, E., Rahutomo, S. (2011). Mucuna bracteata Pengembangan dan Pemanfaatannya di Perkebunan Kelapa Sawit, Edisi II.Pusat penelitian Kelapa Sawit. Medan. 
Mazidah U, Toga Simanungkalit, Irsal. (2014). Uji keefektifan perendaman benih dan pemberian kompos pangkasan mucuna terhadap partumbuhan Mucuna bracteata. Jurnal Online Agroekoteknologi. ISSN No. 2337.

Padmowihardjo, S. (2014). Psikologi Belajar Mengajar. Pengertian Psikologi Belajar Mengajar Dan Definisi Proses Belajar.

Rachmawati H, dan H. (2011). Respon bibit tanaman lada terhadap aplikasi mikoriza indigenous gulma. $J$ Agroteknos., 1((1)), 44-47.

Rini, M., \& Rozalinda, V. (2012). Pengaruh Tanaman Inang Dan Media Tanam Pada Produksi Fungi Mikoriza Arbuskular. Jurnal Agrotropika.

Salwani, S., Amir, H. G., \& Najimudin, N. (2012). Evidence of diazotrophic symbionts in the leguminous cover crop Mucuna bracteata. Pertanika Journal of Tropical Agricultural Science.

Sari, Ramdani, dan R. P. (2015). Rhizobium: Pemanfaatannya Sebagai Bakteri Penambat Nitrogen. Info Teknis EBONI, Vol. 12 No, 51-64.

Siagian, N., Tistama, R. (2005). Perbanyakan Tanaman Penutup Tanah Mucuna bracteata. Warta, Vol 24 (I), 25 - 36. Pusat Penelitian Karet. Medan.

Simarmata, T. (2007). Revitalisasi Kesehatan Ekosistem Lahan Kritis Dengan Memanfaatkan Pupuk Biologis Mikoriza Dalam Percepatan Pengembangan Pertanian Ekologis Di Indonesia. Jurnal VISI, 15((3)), 289-306.

Supriyanto. (1999). The Effectiveness Of Some Ectomycorrhizal Fungi In Alginate Beads In Promoting The Growth Of Several Dipterocarp Seedlings. Biotropia. https://doi.org/10.11598/btb.1999.0.12.148

Surtiningsih T, F. dan T. N. (2009). Biofertilisasi Bakteri Rhizobium pada Tanaman Kedelai (Glycine max (L) Merr). Berkala Penelitian Hayati, 15, 31-35.

Syamsiyah, J., Bambang, H. S., Eko, H dan Jaka, W. (2012). Pengaruh inokulasi jamur mikoriza arbuskula terhadap glomalin, pertumbuhan dan hasil padi. Jurnal. Fakultas Pertanian. Universitas Gajah Mada. Yogyakarta.

Wahyuni, M. dan S. (2019). Jenis - Jenis Pupuk dan Sifat - Sifatnya. Medan: Universitas Sumatera Utara (USU) Press.

Widiastuti, H., \& Sukarno, N. (2005). Penggunaan spora cendawan mikoriza arbuskula sebagai inokulum untuk meningkatkan pertumbuhan dan serapan hara bibit kelapa sawit. Menara Perkebunan. 